\title{
La migración: Un riesgo convertido en amenaza
}

\author{
Shirley Kingman Nevárez ${ }^{1}$ \\ Instituto de Relaciones Exteriores de la Universidad de La Plata-Argentina \\ shirleykingman4@gmail.com
}

\section{Resumen}

La migración desde el enfoque transnacional se entiende como un proceso articulado sobre varios aspectos: social, económico, político y cultural, dando mayor dinamismo tanto a la sociedad de partida como a la de llegada. Sin embargo, éste fenómeno ha venido creciendo como consecuencia de las cuasi dictaduras comunistas que traen consigo pobreza, violación de derechos humanos, violencia, y sobretodo narcotráfico. Actualmente Latinoamérica presenta un incremento de la violencia, lo que al parecer está ligado con la migración de personas ya sea con antecedentes delincuenciales o, con una situación económica y emocional susceptible ante organizaciones criminales que desean engrosar sus filas, agrandar su mercado operacional e imponer su voluntad. El presente trabajo se propone mostrar cómo la migración pasó de ser un riesgo, a convertirse en una amenaza latente, las manifestaciones de éste fenómeno en toda la región, el impacto económico que generan y su vulnerabilidad ante el crimen organizado.

Palabras clave: Migración; amenaza; riesgo; fenómeno; híbrida.

\begin{abstract}
Migration from the transnational perspective is understood as a process articulated on various aspects: social, economic, political and cultural, giving greater dynamism to both the starting and the arriving societies. However, this phenomenon has been growing as a consequence of the quasi-communist dictatorships that bring with them poverty, violation of human rights, violence, and above all drug trafficking. Currently, Latin America presents an increase in violence, which apparently is linked to the migration of people, whether with criminal records or, with an economic and emotional situation susceptible to criminal organizations that want to increase their
\end{abstract}

1. Doctoranda del Instituto de Relaciones Exteriores de la Universidad de La Plata- Argentina. 
ranks, enlarge their operational market and impose their Will. This paper aims to show how migration went from being a risk to becoming a latent threat, the manifestations of this phenomenon throughout the region, the economic impact they generate and their vulnerability to organized crime.

Key words: Migration; threat; risk; phenomenon; hybrid.

\section{Introducción}

"Aunque en américa Latina los conflictos interestatales parecen haber quedado atrás y la mayor parte de las hipótesis de conflicto en clave de seguridad tradicional, es decir de Estado a Estado han sido desactivadas, nuestra región se presenta como la zona sin guerras más violenta del planeta” (Sampó C. 2017, p. 24). Para ir desarrollando el tema en sí, se dividirá en 4 secciones: primero se analiza la transformación del fenómeno migratorio, del riesgo a la amenaza. En la segunda parte, se hará una breve descripción del crimen organizado, sus modos de operación y su influencia en los grupos migratorios. En tercer lugar se plasmarán las manifestaciones que muestran la migración como una amenaza no tradicional que ha ido ganando lugar en las agendas de seguridad de los Estados Latinoamericanos. Y finalmente en las conclusiones, se muestran las causas de la expansión migratoria, los costos que ésta genera y las consecuencias que trae consigo.

\section{La Migración, riesgo convertido en amenaza}

Fue en la década de los 80, que se dio inicio al estudio de éste fenómeno migratorio, dando una mirada simultánea en origen y destino, formulándose nuevos cuestionamientos sobre este tema con respecto a los vínculos, prácticas y relaciones tanto familiares, como culturales, económicas, políticas y religiosas que se inscriben más allá del territorio nacional, lo que sin duda le imprimía dinamismo tanto a la sociedad de acogida como a la de partida. No es sino, a inicios de 1990 que se introduce el transnacionalismo como marco teórico, para entender de forma global éste fenómeno, permitiendo ampliar el campo de investigación al respecto y, sacándolo del estrecho marco de Estado - Nación. Así, la inmigración puede ser definida como un proceso de construcción de redes, que dependen de las relaciones sociales a través del espacio. Es por esto, que de forma casi natural los grupos migratorios buscan unirse con el fin de mantener sus costumbres y tradiciones. 
Ya en 1991 en la Consulta de Santiago de Chile, las definiciones de las amenazas tradicionales y nuevas amenazas a la seguridad de los Estados, tuvieron su primer impulso, considerándose inicialmente como preocupaciones. Pero más adelante en la Declaración sobre Seguridad de las Américas, el 28 de octubre del 2003 en México, dentro de los nuevos lineamientos de desafíos, se plantea el surgimiento y presencia de nuevas amenazas en el siguiente orden:

1.- Amenazas duras a la seguridad, dentro de ellas terrorismo, delincuencia organizada transnacional, narcotráfico, corrupción, lavado de dinero, tráfico ilícito de armas.

2.- Amenazas de origen social con impacto a la seguridad como la exclusión y la pobreza.

3.- Amenazas provenientes de la naturaleza y la salud como: desastres naturales y aquellos producidos por el hombre, deterioro del medio ambiente, sida y otras pandemias.

4.- Amenazas contra la integridad de las personas originadas por causas sociales, pero realizadas por grupos de crimen organizado como: la trata de personas.

5.- Amenazas on line: los delitos cibernéticos.

6.- Amenazas provenientes de transporte de productos peligrosos: desechos tóxicos, petróleo, material radioactivo, y;

7.- Amenazas por posible posesión de armas de destrucción masiva por parte de personas o grupos terroristas que pueden actuar en el hemisferio.

Como podemos notar cuando se establecieron estos lineamientos, ni siquiera se consideraba el tema de la migración, porque ésta no era una amenaza dura, sino sólo una preocupación. Sin embargo, el hemisferio tiene problemas estructurales serios, como la extrema pobreza, violación de derechos humanos, falta de transparencia, inestabilidad institucional y económica, corrupción, alto grado de desigualdad y los flujos migratorios no controlados. Este último, erróneamente considerado una preocupación según el consenso de NNUU, compuesto por sólo 5 Estados, que además son países desarrollados.

Desde el año 2007 comenzó una migración masiva, sobretodo de ciudadanos venezolanos que huían de las consecuencias de la dictadura bolivariana, como la extrema pobreza, el narcotráfico, la violencia, muerte y corrupción, hacia otros Estados subdesarrollados con realidades diferentes, siendo estos quienes realmente deben definir, evaluar, conceptualizar, 
escribir e ideologizar éste fenómeno, por ser países receptores de la migración, que son los que sufren las repercusiones negativas de éste hecho, que afecta la salubridad, distrae los recursos de ese Estado, hace caso omiso de la legislación de ese país, produce necesidades en las situaciones de ayuda propias que da a la población; genera mayor competitividad en ese mercado y en general, va quitando fuentes de trabajo para los nacionales, creando resentimiento y exacerbando la xenofobia de la población local hacia los migrantes y las instituciones públicas y privadas, que los acogen por encima de los nacionales quienes buscan desesperadamente un empleo para establecerse y cubrir no sólo sus necesidades sino las de su núcleo familiar.

Pero más grave aún, cuando los grupos migratorios, no logran satisfacer sus necesidades básicas, se vuelven generadores de violencia por razones famélicas; es decir, si no tienen que comer, no les interesa si obtienen comida de manera legal o ilegal porque tienen el derecho a sobrevivir. Entonces sí se vuelven una amenaza para la población, cuando como respuesta a la frustración lógica que les supone ir a vivir a un territorio extraño; participan en acciones como las que se vienen dando en América Latina inicialmente en Ecuador, con el levantamiento indígena, donde no sólo fueron actores, sino quienes propiciaban la violencia de una manera a la que no estamos habituados.

Ciertamente no se puede generalizar, pero si se puede definir que dentro de los flujos migratorios no controlados, pueden ingresar personas buenas y también personas con antecedentes delictuales que representan una grave amenaza para el país de acogida, entendiéndose como amenaza al peligro perentorio que surge de un hecho, o acontecimiento que aún no ha sucedido, pero que de concretarse como es el caso, perjudica a toda una población.

Según Pérez Porto y Merino (2015) éste término puede emplearse incluso, como referencia al "inminente desarrollo de algo negativo". En otras palabras, los migrantes se vuelven una amenaza cada vez mayor, puesto que son elementos susceptibles para ser reclutados por el crimen organizado, en sus diferentes expresiones, pues "el crimen organizado no es un tipo de delito en particular, sino una forma de cometer delitos, caracterizada por dos condiciones: cierto nivel de planificación, y la participación conjunta y coordinada de varios individuos" (De la Corte Ibáñez y Giménez Salinas Framis, 2015, p.19) 
Como consecuencia de estos hechos, la ONU recientemente organizó en Bruselas una reunión para analizar las medidas que deben tomar los Estados receptores en cuanto a la crisis migratoria, sus consecuencias y el impacto económico que trae consigo.

\section{Crimen organizado y sus modos de operación, así como su influencia en los grupos migratorios}

Como ya se había mencionado en la primera parte de éste trabajo, la Declaración sobre Seguridad de las Américas de México 2003, abre paso a una nueva estructura del pensamiento sobre Seguridad, esta vez desde una visión multidimensional que incluye amenazas tradicionales y nuevas amenazas, entre otros desafíos, respetando por supuesto los valores democráticos, derechos humanos, solidaridad, cooperación y la soberanía de los Estados; así como sus prioridades para tratar sus problemas de seguridad, de tal forma que contribuyan a la paz integral, desarrollo y justicia social.

Dentro de esas nuevas amenazas, se encuentra el "crimen organizado, que se transformó en una de las más peligrosas amenazas transnacionales de la post Guerra fría" (Bartolomé, 2006, p. 165) y los retos que actualmente ésta genera a las sociedades latinoamericanas; así como la densa trama que se teje entre la corrupción, el lavado de dinero, el tráfico de personas, de armas y de drogas que maneja. Estas manifestaciones que se dan en toda la región, junto a las vulnerabilidades sociales y del medio ambiente como la exclusión social, la extrema pobreza, los desastres naturales y aquellos producidos por el hombre, VIH, flujos migratorios no controlados, terrorismo, etc., son debilidades estructurales que sin duda, aprovecha éste fenómeno para obtener ventajas económicas y ampliar su capacidad de gestión criminal.

El crimen organizado en América Latina tiene diferentes modus operandi que indiscutiblemente van de la mano con el narcotráfico, un delito complejo que incluye tráfico: de drogas, armas (municiones y explosivos), personas (trata, órganos), dinero (lavado de activos), recursos naturales, mercancías (contrabando y falsificaciones), etc. Todas, actividades económicas ilegales que responden a una demanda de bienes o servicios prohibidos; pero no son necesariamente las políticas de prohibición, las que agravan el problema sino más bien, el rechazo de la sociedad civil y la debilidad de los Estados con manifiesta dificultad para controlar los flujos que traspasan sus fronteras y por supuesto la corrupción, herramienta sin la cual al 
crimen organizado le sería difícil e incluso imposible de operar. De allí que "la existencia de la corrupción política y del crimen organizado se hallan íntimamente relacionados" (Aldá Mejías, 2015, No.37).

\section{- Tráfico de drogas}

El narcotráfico es sin duda, la actividad delictiva que más dinero mueve y reporta en nuestra región, creando una explosión de actividades ilegales de diversa índole que involucra el cultivo, la manufactura, la distribución y venta de sustancias ilegales desde mercados pequeños, hasta mercados de droga de gran escala donde la lucha por la producción y la comercialización de los estupefacientes da cuenta de la magnitud del negocio.

Cabe mencionar, que los 3 países principales de producción de cocaína (una de las drogas de mayor consumo a nivel mundial) se encuentran en Sudamérica (Perú, Colombia y Bolivia) mientras que el principal mercado de consumo de esta droga (Estados Unidos) se encuentra al norte del mismo continente, siendo Brasil por la cantidad de consumidores, el segundo mercado a nivel regional y; Argentina de acuerdo al porcentaje de su población económicamente activa que ha consumido cocaína alguna vez, es uno de los usuarios más importantes a nivel global. Pero además ambos países, son fundamentales rutas de tránsito (UNODC, 2015).

\section{- Tráfico de Personas}

El tráfico de seres humanos, que dicho sea de paso genera ganancias extraordinarias, tiene dos aristas: la trata y el contrabando de personas. La trata no es otra cosa sino la explotación con fines sexuales o laborales. O como lo define Naciones Unidas (2004), es "la captación, el transporte, el traslado, la acogida o la recepción de personas, recurriendo a la amenaza o al uso de la fuerza u otras formas de coacción, al rapto, al fraude, al engaño, al abuso de poder o de una situación de vulnerabilidad o a la concesión o recepción de pagos o beneficios para obtener el consentimiento de una persona que tenga autoridad sobre otra, con fines de explotación".

En la trata de seres humanos, se destaca una particularidad y es que las personas pueden ser vendidas varias veces, con finalidades distintas cada vez. Por ejemplo, ingresan a una red criminal ya sea a través de secuestro, venta por parte de sus progenitores o engaños mediante 
ofrecimientos de trabajos atractivos con buena remuneración, convirtiéndose sin saber en esclavos modernos y les retienen sus documentos, los golpean, los violan y los amenazan de muerte a ellos o a sus familias si es que intentan huir, a fin de explotarlos sexualmente. Pero este escenario puede cambiar con el tiempo al bajar su rendimiento, ya que pasan a ser explotados laboralmente, en talleres de costura clandestinos o en trabajos agrícolas o domésticos, para luego de unos años si mantienen un buen estado de salud puedan ser vendidos para que sus órganos sean traficados.(Naím, 2006) pues según Pérez Salazar (2014) se estima que el 10\% de los trasplantes realizados, utilizan como insumo un órgano que no ha sido conseguido de manera legal.

De otra parte, el contrabando de seres humanos, se da de común acuerdo entre el migrante y la persona que lo ayuda a ingresar de manera ilegal a un determinado país, violando deliberadamente las regulaciones migratorias. Este acuerdo puede sufrir cambios en el trayecto, que terminen en el abandono del migrante en medio de la frontera, el ingreso a un país distinto o, en el peor de los casos, en su muerte si se presentan dificultades con las autoridades de control migratorio.

Según la Convención de las Naciones Unidas contra la Delincuencia Organizada transnacional y sus protocolos (UNODC 2004), el contrabando de migrantes implica la obtención de beneficios financieros o materiales, del ingreso ilegal de una persona a un país, del que no es ni nativo ni residente.

\section{- Tráfico de armas}

Durante el periodo de la Guerra Fría, como postula Álvarez (2016) por motivos geopolíticos se inició un mercado de armas pequeñas alimentado por la transferencia de estos dispositivos desde las potencias en pugna, Estados unidos y la ex Unión de Repúblicas Socialistas Soviéticas (URSS), hacia los países del tercer mundo con la finalidad de ganar influencia política en zonas categorizadas como estratégicas, creándose una rivalidad bipolar, que alimentó gran parte de los conflictos armados en América Latina suministrando de forma directa o mediante terceros, armas a las facciones beligerantes. $\mathrm{Y}$ en efecto, el aumento de grupos armados ilegales de distinta orientación en Latinoamérica, generó una importante demanda de armas ligeras y automáticas, especialmente fusiles de asalto, así como la proliferación del tráfico de estos dispositivos pequeños y livianos en el mercado ilegal, lo que está íntimamente 
relacionado con la capacidad de desestabilizar el orden social vigente, que las mismas pueden llegar a tener; así como también con los índices de violencia que denota la región y el efecto que estos tienen sobre la (in) seguridad pública. En especial considerando la cantidad de homicidios cada 100 mil habitantes que detentan los países de la región.

Cabe mencionar que para el crimen organizado, éste es un negocio por demás rentable, que además suele ser la contracara de las redes de distribución de drogas. Según el protocolo contra la fabricación y el tráfico ilícito de armas de fuego éste delito consiste en la adquisición, venta, entrega, traslado o transferencia de armas de fuego, sus piezas fundamentales o componentes esenciales y municiones desde, ó a través del territorio de un Estado parte, al de otro Estado parte.

\section{- Tráfico de dinero}

Esta actividad ilícita conocida también como lavado de activos, genera beneficios que se terminan reflejando en el desarrollo de actividades legales. Esto gracias a la "necesidad de camuflar los enormes beneficios obtenidos por vía ilegal, es decir, la necesidad de blanquear el dinero sucio" (De La Corte Ibáñez y Giménez-Salinas Framis, 2015, p.25)

El crimen organizado necesita capital para obtener negocios que funcionen como fachadas de sus empresas ilegales; así como también para transportar, entrenar y pagar a funcionarios públicos corruptos que facilitan sus negocios, disimulando el producto de sus crímenes, al convertirlos en bienes y servicios que les permitan inyectar dinero proveniente de actividades ilegales en la economía formal, haciéndolo parecer legítimo.

Una de las formas de "Blanquear" el dinero que más se ha desarrollado en los últimos tiempos es la compra de inmuebles o jugadores de fútbol, pero también existen: la compra de oro, de instrumentos monetarios como cheques de viajero o cheques al portador, contrabando de dinero de un país a otro, transferencias de dinero y prácticas bancarias informales, como el sistema "hawala", muy usado en medio Oriente, que consiste en el envío de dinero alternativo para depositar en cuentas bancarias sin posibilidades de ser rastreadas, sin gastos bancarios ni demoras en las transferencias.

\section{- Tráfico de Recursos Naturales}


A pesar de los controles que existen para evitar la explotación ilícita de recursos naturales, el crimen organizado saca rédito de la evasión de dichos controles, afectando negativamente a los países emergentes porque sus economías dependen de la extracción de dichos recursos en algunos casos no renovables como el petróleo, diamantes, oro y otros metales valiosos, con los que ya no pueden contar; además de que sus gobiernos no tienen la capacidad para regular eficientemente la explotación de los mismos. Así, si consideramos la deforestación o incluso el vertido de sustancias tóxicas o radiactivas, veremos el impacto directo que esto tiene no sólo en la calidad de vida de las personas, sino en la flora y la fauna de esos países.

\section{- Mercancías}

Así mismo el tráfico de mercancías, cigarrillos, alcohol, electrónica e incluso indumentaria, permite alcanzar grandes beneficios evitando aranceles e impuestos sobre ciertos artículos de consumo, pero que además acarrea poco riesgo, para llegar a un mercado reducido de consumidores que desean bienes de lujo evadiendo las obligaciones tributarias que muchas veces incrementan el valor del producto en un 25\%. En ésta línea de contrabando se incluyen las falsificaciones o imitaciones como por ejemplo programas informáticos, medicamentos adulterados o falsificados. Aparece entonces el "mercado gris" donde fábricas que elaboran productos bajo licencia en horario habitual, muchas veces hacen doble turno y producen el mismo bien para venderlo por fuera de los canales legales y a un precio mucho más bajo.

Como ya se ha mencionado, varias son las formas de operación del crimen organizado transnacional que engrosa sus filas a través de redes de reclutamiento de personal, en su mayoría gente con escasos recursos que cargan a sus espaldas, la falta de trabajo para llevar el sustento a casa, el hambre, la discriminación, la actitud hostil como causa de inestabilidad en todo sentido y el proceso migratorio cada vez más complejo por el que tiene que pasar.

\section{Manifestaciones que muestran a la migración como una amenaza no tradicional}

Frente a la exponencial difusión y deslocalización actual de los conflictos desarrollados en las últimas semanas, éste trabajo permite echar una ojeada -desviándose un poco pero necesariamente del tema- a distintos elementos que hoy en día se conocen como amenazas 
hibridas, mismas que se diferencian de una guerra, porque mientras ésta última lleva implícito el uso de la violencia física, las amenazas no necesariamente acuden al uso de la misma, sino más bien a nuevos campos de acción relacionados con varios elementos de poder, de sumisión e influencia, como: la información, la política, la economía, las finanzas, movimientos sociales, infraestructuras críticas, ataques a sitios web, redes sociales y otros que afecten incluso la cultura, el prestigio y el orden social. Todos estos son medios no convencionales o no-militares basados en la proactividad; es decir en el ataque al enemigo, que en estos casos son los gobiernos de turno y no en la defensa propia, a fin de imponer su voluntad. (Mazurier, Payá Santos, 2018, p.52)

La RAE define híbrido en los siguientes términos: "Dicho de una cosa: Que es producto de elementos de distinta naturaleza". En otras palabras, la esencia de la hibridez, es la mezcla de elementos de distinta naturaleza, cuya combinación produce un determinado resultado.

Ante las últimas revueltas que se dieron en España y que, lejos de ser manifestaciones y marchas pacíficas, estaban más bien cargadas de violencia, saqueos y destrucción tanto de bienes públicos como privados, y que luego se vivieron en Ecuador empezando con el levantamiento indígena, más adelante en Chile, todas aparentemente como una reacción violenta ante las nuevas medidas económicas; y actualmente en Bolivia como resultado del triunfo fraudulento del Presidente Morales, surge la interrogante sobre, si esto realmente es una muestra de rechazo a las decisiones del gobierno o si obedece al cumplimiento de la agenda de una corriente política, en vista de que tanto en Chile como en Ecuador, se detectaron grupos terroristas infiltrados en las manifestaciones, formados por migrantes cubanos y en su mayoría, venezolanos, que expusieron a la población a actos vandálicos; por demás violentos contra los medios de comunicación y la fuerza pública, que incluso fueron secuestrados y vilipendiados, golpeándolos y quemando sus vehículos, destruyendo totalmente la infraestructura de algunas microempresas, instituciones públicas como la Contraloría General del Estado y el producto de grandes exportadoras, así como privando a la ciudadanía de servicios básicos en algunos sectores de la capital ecuatoriana.

Todos estos hechos, nunca antes vistos y muy similares por cierto, crean la necesidad de generar un cambio urgente en las agendas de seguridad de los Estados, tomando en consideración las nuevas amenazas para las que no estaban preparados y cuyo procedimiento, al parecer se encuentra detallado en el llamado Foro de Sao Paulo, creado en 1989 tras la caída del Muro de Berlín. Su objetivo, establecer en América Latina, la unión de países bajo gobiernos 
comunistas para tomar el control de toda la región hispana, logrando así que Sudamérica, El Caribe y España, se conviertan en sociedades progresistas o también conocidas en otros términos, desde el punto de vista político como: Liberalismo, Izquierdismo o Comunismo, entre otros; es decir, en la Unión soviética Hispana, que reemplazaría a la desaparecida URSS con la creación de "nuevas estrategias" que permitan aprovechar las debilidades de los gobiernos democráticos, o temas sensibles como el aborto, el medioambiente, la identidad de género, etc., para ganar espacios de poder. Es importante mencionar además que los temas antes mencionados no dejan de ser otras amenazas latentes, que generan sentimientos de rechazo en una población cansada de los fracasos políticos, que se vuelve vulnerable ante los ofrecimientos de una vida llena de subsidios y gratuidades, con el menor esfuerzo posible; del "abandono de la lucha armada", refiriéndose por supuesto a la fuerza pública de los Estados que ha sido debilitada, más no a las fuerzas de choque creadas por estos grupos y a las que han ido fortaleciendo, con el único propósito es perennizarse en el poder, institucionalizando así, el “populismo”.

Un claro ejemplo de esto son Cuba y Venezuela. En ésta última, a causa de la crisis política, económica y social en la que está sumida, se ha ido incrementando el número de personas que abandonan su país, aumentando las cifras a partir del 2012, por lo que según datos de la ACNUR y la OIM (2016) ha migrado 3,4 millones de venezolanos, de los cuales 2,7 se encuentran en América Latina, siendo Colombia el principal país de acogida por ser frontera con Venezuela, otros en Perú, Chile, Argentina, Brasil y unos 300 mil en Ecuador. En la actualidad alrededor de 5.000 venezolanos salen a diario de su país, lo que representa un aumento del gasto público, mayor competencia en el mercado laboral y por supuesto un crecimiento desmedido de la delincuencia, cada vez más violenta.

Todo esto, como lo ha calificado la Secretaría General de la OEA (2019) es consecuencia de las dictaduras bolivariana y cubana que buscan nuevamente reposicionarse, a través de su vieja metodología, esencialmente financiar, apoyar y promover el conflicto político y social. De hecho, ante los últimos acontecimientos, el partido de gobierno venezolano insistió en exaltar las revueltas y desmanes que se dieron en algunos países, calificándolas como "brisas bolivarianas" que representan un avance de los movimientos de izquierda para captar el poder. Pero la realidad, es que son una corriente desestabilizadora que ha traído violencia, narcotráfico, muerte y corrupción. Un terreno fértil para el crimen organizado, que aprovecha la situación para reclutar 
en sus filas, a los migrantes que llegan en extrema pobreza e inestabilidad, además de la hostilidad que representa el encontrarse en un país extraño, sin trabajo, comida, ni vivienda.

\section{Costos}

A partir del 2008 en que se creó la nueva Constitución ecuatoriana en la que se promueve la libre movilidad humana y la búsqueda de la ciudadanía universal; ha ido creciendo el número de migrantes que ven en Ecuador un país de destino, por tener moneda dura y por todas las facilidades que el gobierno anterior les daba, entre ellos la no exigencia de una visa para ingresar. Pero ante la oleada de delincuencia violenta que se desató en el país, el siguiente gobierno decidió que desde el 24 de Mayo del 2019, día en que rindió su informe a la nación, se extienda hasta el 26 de agosto del mismo año una "visa humanitaria" que consistía en presentar su documentación personal incluyendo el pasado judicial, para residir y trabajar en ese país por un lapso de 2 años, pudiendo durante ese tiempo aplicar a la regularización ofrecida por el gobierno ecuatoriano.

Pero la población migrante venezolana rechazó esta decisión alegando que no querían quedarse en Ecuador, sino entrar de tránsito para luego dirigirse a Perú. Por lo que se creó un corredor que facilitaba el traslado hasta la frontera sur para que puedan seguir al Perú, situación que se empeoró porque el país vecino del sur, cerró sus fronteras a partir del 15 de Junio del 2019 a todos los venezolanos, a menos que soliciten una visa en los Consulados de Perú en Venezuela. Este panorama cada vez más entramado, dificulta el viaje de los migrantes que ciertamente no quieren quedarse en Perú, sino avanzar hasta el sur del continente, pero Chile y Argentina también tomaron medidas migratorias. Chile por ejemplo, anunció reformas en su legislación para que los venezolanos que quieran quedarse en ese país, soliciten una visa desde su origen en Venezuela, mientras que Argentina reformó su ley de extranjería con más controles, desmoronándose así el esquema de UNASUR, que permitía tener una visa de residencia por dos años.

Todos estos procesos desde el recibir a los migrantes o trasladarlos hacia una frontera para que continúen su camino, generan costos a cada Estado; particularmente al Ecuador según la Cancillería del mismo país le han representado más de 120 millones de dólares, el monto que se requiere para afrontar sólo las necesidades de la migración venezolana que bordea un ingreso de 300.000 ciudadanos de ese país. Pero cabe mencionar otras cifras, como por ejemplo que entre el 
2012 y 2019 el Ecuador otorgó 126.000 visas a venezolanos y que en el mismo periodo, se regularizó la situación migratoria de 108.000 colombianos, 60.000 cubanos, 55.000 chinos, 34.000 estadounidenses y 20.000 peruanos. Es decir, que "aproximadamente en estos 10 años, 416.000 personas fueron regularizadas en el Ecuador" generando en la economía nacional un gran impacto. Es decir, que el Ecuador requería un presupuesto estimado de 117.3 millones de dólares adicionales, de acuerdo a las cifras del plan de respuesta para refugiados y migrantes, que estableció las NNUU y Organizaciones de la Sociedad Civil, ya que según la Cancillería, "no se trata solamente de atender a los migrantes, sino de afrontar el origen de ésta crisis" (MINISTERIO DE RREE - ECUADOR, 2019), pues "a los 4 millones y medio de migrantes refugiados venezolanos, se sumarían posiblemente 2 millones más en el 2020, aumentando así las necesidades de ayuda en los países de acogida.” (ONU, 2019).

\section{Conclusiones}

En la Declaración sobre Seguridad de las Américas en México 2003, se definieron amenazas tradicionales y nuevas amenazas como por ejemplo la exclusión, la pobreza, flujos migratorios no controlados y aquellas que van contra la integridad de las personas, todas originadas por causas sociales, pero realizadas por grupos de crimen organizado como el contrabando y la trata de personas, el tráfico de órganos, drogas, etc.

Este enfoque que se dio en el año 2003 incluye a los procesos migratorios, pero los define casi como una preocupación, porque las NNUU se basaron en la fundamentación de los países que tienen voto dirimente y porque casi siempre la migración se dio desde los países del tercer mundo hacia los países desarrollados en busca de mejores oportunidades como por ejemplo los mexicanos, que se iban a Estados Unidos, o en el caso de otros países latinos, la migración se daba hacia España donde ganaban en Euros. En ambos casos su situación mejoraba y podían mandar remesas a sus países de origen, pero la situación fue cambiando a raíz del aparecimiento del famoso Socialismo del siglo XXI como una presencia regional que derivó en un proceso migratorio diferente, porque se da entre países del tercer mundo y más aún, cuando notaron que había en la región países dolarizados como Panamá y Ecuador, donde también podían ganar en moneda dura y enviar a sus familias ya sea para que subsistan o para que también migren, obligados por la implantación forzosa de una ideología que definitivamente no demostró ser 
exitosa en ninguno de los países en los que se radicó. Lamentablemente los flujos migratorios, fueron trayendo paralelamente sus otros problemas, para usarlos en actividades ilícitas.

Este socialismo del siglo XXI, nombre con el que apareció, pero que fundamentalmente comenzó a desarrollarse mediante los trabajos que realizó la CEPAL con las corrientes económicas que planteó para las doctrinas en las que enfocaba las diferencias entre Norte - Sur, el imperialismo Yanky y los países olvidados o subdesarrollados, etc. Dichos trabajos, que representaban en realidad un caldo de cultivo para crear rivalidad, influenciaron negativamente tanto en los movimientos culturales, como en la academia paralelamente, implantando una ideología que junto con los procesos migratorios -que dicho sea de paso se dieron por condiciones económicas dramáticamente insostenibles- queda reflejada en una nueva forma de protesta o manifestación popular violenta, que es la que estamos viviendo actualmente.

Esta nueva ideología que trajo de la mano una migración masiva, sirvió como instrumento para la delincuencia organizada transnacional, actuando en actividades ilícitas tales como el narcotráfico; tráfico de influencias; coimas millonarias; entre otras. En el caso de los migrantes, siendo usados como mulas; en la trata o el contrabando de personas; para la prostitución; tráfico de órganos; o como fuente barata de trabajo para explotarlos en el mercado gris; es decir, la utilización del hombre por el hombre no con fines ideológicos y no ideológicos, sino protervos y criminales.

Esta fenomenología y las consecuencias que paralelamente ha traído consigo, es la que está desarrollando un proceso sin sentido en una sociedad en la cual el postmodernismo, la ha llevado a perder la fe en todos los procesos ideológicos, en los procesos políticos y a buscar alternativas económicas, en las cuales está transversalmente introducida la ideología Socialista Cepalina de los procesos del Neo estructuralismo, eje principal que incluye fuertes brotes de violencia, que se están sumando a este intento de desestabilización democrática en la región.

Sin embargo, no hay que perder de vista que en el caso de Venezuela, una solución duradera a la crisis migratoria, yace en la salida pacífica, democrática y enmarcada en la ley del régimen Chavista, para dar paso a elecciones transparentes. 


\section{Referencias}

SAMPÓ, Carolina. (2017). El crimen organizado en América Latina: Manifestaciones, facilitadores y reacciones.

ALDÁ MEJÍAS, Sonia. (2015). La debilidad del imperio de la ley en América Latina: Un factor para entender la implantación del crimen organizado. Revista española de Ciencia Política No.37

ALVAREZ, C. (2016). Armas pequeñas y países pequeños: armas de fuego en la agenda de seguridad internacional, Icono. Revista de Ciencias Sociales No. 55

BARTOLOMÉ, Mariano. (2006). La seguridad internacional en el siglo XXI, más allá de Westfalia y Clausewitz. Santiago de Chile: Ministerio de Defensa Nacional.

DE LA CORTE IBÁÑEZ, L. Y GIMÉNEZ - SALINAS FRAMIS, A. (2015). Crime. Org. Barcelona, Ariel Editorial.

LYMAN, M. Y POTTER, G. (2015). Organized Crime 6ta. Edición Boston Pearson MAZURIER, Pablo Andrés. PAYÁ SANTOS, Claudio. (2018). Amenazas Híbridas: teoría de la hibridez y nuevo orden internacional.

NAÍN, M. (2006). Ilícito: Cómo traficantes, contrabandistas y piratas están cambiando al mundo. Barcelona: Debate.

PÉREZ PORTO Julián. MERINO, María .(2015). Definición de Amenaza. Recuperada de (https:definicion.de/amenaza/)

PÉREZ SALAZAR, J. (2014). La realidad sobre el tráfico de órganos en el mundo. BBC (2014) RODRÍGUEZ MANZANO, Irene. (2007). Las migraciones en el contexto internacional. En Revista Española de Desarrollo y Cooperación, No 19.

ACNUR, OIM. (2016). (Recuperado de https://www.acnur.org/situacion-en-venezuela.html_y http://www.oim.org.ec/2016/iomtemplate2/news/el-número-de-refugiados-y-migrantes-devenezuela-alcanza-los-3-millones)

Ministerio de Relaciones Exteriores del Ecuador. (2019). (Recuperado de https://www.cancilleria.gob.ec/) 
OEA .(2019). (Recuperado de

https://www.oas.org/es/centro_noticias/comunicados_prensa.asp?nMes=10\&nAnio=2019).

ONU (2019) Recuperado de https://www.un.org/es/about-un/

UNODC (2004) Convención de las Naciones Unidas contra la delincuencia organizada

transnacional y sus protocolos. New York. Recuperado de

https://www.unodc.org/pdf/cld/TOCebook-s.pdf

UNODC (2015) Research, World Drug Report. Recuperado de

https://www.unodc.org/documents/mexicoandcentralamerica/eventos/2015/WDD2015/World_Dr

ug_Report_2015.pdf

Shirley Kingman Nevárez * 2

2

* Coordinadora, Red Académica Internacional Dávila \& Dávila 